\title{
Optimization of the diffraction efficiency in photorefractive crystals
}

\section{Optimización de la eficiencia de difracción en cristales fotorrefractivos}

\author{
Astrid Lorena Villamizar Amado¹, Néstor Alonso Arias Hernández², Martha Lucía Molina \\ Prado $^{2}$, Myrian Tebaldi ${ }^{3}$ \\ 1. Estudiante de Física, Semillero COUP - Grupo de Óptica Moderna, Departamento de Física y Geología,
Universidad de Pamplona \\ 2. Grupo de Óptica Moderna, Departamento de Física y Geología, Universidad de Pamplona \\ 3. Centro de Investigaciones Ópticas (CONICET La Plata, CIC) and UIDET OPTIMO, Facultad Ingeniería, \\ Universidad Nacional de La Plata, Argentina. \\ ${ }^{(*)}$ E-mail: molinaprado@gmail.com
}

Received: 02/12/2016 Accepted: 05/05/2017

DOI: $10.7149 /$ OPA.50.2.49044

\begin{abstract}
:
The aim of this work is to study and to optimize the diffraction efficiency in sillenite BTO crystals. A theoretical analysis, where the effects of coupling beams are significant, is carried on. In addition, non-mobile transmission gratings are considered. The diffraction efficiency is obtained by using the coupled wave equations in on-Bragg regime using Method Runge-Kutta of order 4 in Matlab. Also, the non-uniformity of the gratings inside the crystal sample, the optical activity of the material and the polarization of the recording beams are taken into account.
\end{abstract}

Key words: Photorefractive crystals, diffraction efficiency.

\section{RESUMEN:}

En este trabajo se estudia la eficiencia de difracción en cristales silenitas BTO. Se presenta un análisis teórico en donde los efectos de acoplamiento son tenidos en cuenta. Además, se consideran redes nomoviles de transmisión. La eficiencia de difracción es obtenida a través de la solución de las ecuaciones acopladas en el regimen on-Bragg usando el método de Runge-Kutta de orden 4 implementado en Matlab. La no uniformidad de las redes dentro del cristal, la actividad óptica del material y la polarización de los haces son tenidos en cuenta.

Palabras clave: Cristales fotorrefractivos, eficiencia de difracción.

\section{REFERENCES AND LINKS / REFERENCIAS Y ENLACES}

[1] Yeh, "Introduction to Photorefractive Nonlinear Optics," Wiley, New York, (1993)

[2] L.F. Magaña, I. Casar, J.G. Murillo, "Beam energy exchange in sillenite crystals (Bi12SiO20 and Bi12Ti020), considering the variation of light modulation along sample thickness in a strong nonlinear regime," Opt. Mater. 30, 979-986 (2008). https://doi.org/10.1016/j.optmat.2007.05.026

[3] Marrachi, A., Johnson, R.V, Tanguay, Jr.A.R "Polarization properties of photorefractive diffraction in electrooptic and optically active sillenite crystals (Bragg Regime), J. Opt. Som. A. B, (1986) 
[4] Gonzales, G., Zuñiga, A. “Optimization of the diffraction efficiency in nonuniform gratings in sillenite crystals considering the variation of fringe period, optical activity and polarization angles in a strong non-linear regime," Revista Mexicana de Física, (2009)

[5] Molina Prado M.L., et al. "Medida de la eficiencia de difracción fotorrefractiva como función del vector de onda de la red en un cristal BTO,” Bistua, 9 (2), 43-47 (2011).

[6] Molina M.L. et al, "Eficiencia de difracción del registro de speckle modulados generados a partir de superficies reflecto-difusoras," Bistua, 10 (2), 2012.

[7]. J.G. Murillo, L.F. Magaña, M. Carrascosa and F. Agulló-López, "Temporal evolution of the physical response during photorefractive grating formation and erasure for BSO". J. Appl. Phys. 78. 5686 (1995) https://doi.org/10.1063/1.359626

[8] C.L. Woods, C.L. Matson and M.M. Salour, "Crystallographic fringe orientation diffraction efficiency in bismuth silicon oxide". J. Appl. Phys. A 40, 177-182 (1986) https://doi.org/10.1007/BF00617401

[9]. J.P. Herriau, D. Rojas, and J.P. Huignard, "Highly efficient diffraction in photorefractive BSO-BGO crystals at large applied fields". Ferroelectrics 75, 271-279 (1987) https://doi.org/10.1080/00150198708008227

\section{Introduction}

The photorefractive effects in electrooptical crystals have been widely studied for applications to realtime holography, optical data storage, and more recently for phase-conjugate wavefront generation [1-6]. The high recording sensitivities combined with crystal quality and availability has been found in a cubic, paraelectric and electrooptic $\mathrm{Bi}_{12} \mathrm{TiO}_{20}$.

The nonuniform pattern received by the crystal results in a refractive index change due to the photorefractive and linear electro-optic effect. The optimum diffraction efficiency has been observed for two different orientations of the crystallographic axes with respect to the space charge field Esc [3]. The sign of the charge carriers, which cause the space-charge field, can be determined by the energy transfer direction and the electro-optic coefficient measurements.

In this work we considered non-moving transmission gratings under an applied field, the variation of fringe period and we included optical activity and birefringence in the Bragg-regime. One crystal orientation is considered, with the grating vector is parallel to the face [001].

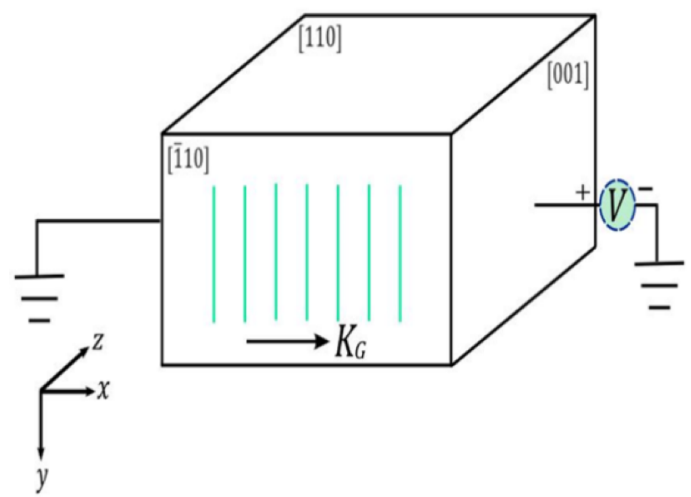

Fig.1: Longitudinal holographic configuration $\overrightarrow{K_{G}} \|<001>$.

\section{Set Coupled Wave Equations}

The BTO is a material with electrooptic coupling and optical activity, the wave equation that governs light propagation is: 


$$
\nabla^{2} \vec{E}+\frac{k_{0}^{2}}{\epsilon_{0}} \vec{D}=0
$$

where $\vec{E}$ is the total light field, $k_{0}=2 \pi / \lambda$ is the magnitude of the optical wave vector, $\lambda$ is the wavelength and $\epsilon_{0}$ is the free space permittivity.

For a birefringence medium with optical activity and electro-optic coupling, this constitutive relation can be expressed in the form:

$$
D_{i}=\epsilon_{0}\left(\epsilon_{i j}+G_{i j}+\Delta \epsilon_{i j}\right) E_{j} ;
$$

where $\mathrm{G}_{\mathrm{ij}}$ is the optical activity antisymetric tensor, $\Delta \epsilon_{\mathrm{ij}}$ is the change in the permittivity tensor induced by the electrooptic effect and $\epsilon_{\mathrm{ij}}$ is the symmetric optical permittivity tensor.

For the $\overrightarrow{\mathrm{K}_{\mathrm{G}}} \|<001>$ orientation, the $\mathrm{x}$ axis is parallel to the $<001>$ crystallographic axis, as show in Fig. 1. The transformation matrix that converts from the crystallographic system to the light propagation system is:

$$
\mathrm{T}=\left[\begin{array}{ccc}
0 & 0 & 1 \\
-1 / \sqrt{2} & -1 / \sqrt{2} & 0 \\
1 / \sqrt{2} & -1 / \sqrt{2} & 0
\end{array}\right]
$$

For this orientation, the permittivity tensor, exclusive of optical activity components, is:

$$
\epsilon_{\mathrm{ij}}=\left[\begin{array}{ccc}
\epsilon & 0 & 0 \\
0 & \epsilon+\Delta \epsilon & 0 \\
0 & 0 & \epsilon-\Delta \epsilon
\end{array}\right]
$$

If $\Delta \epsilon=n_{0}{ }^{3} r_{41} E_{x}$, where $n_{0}$ is the index of refraction, $r_{41}$ is electrooptic coefficient and $E_{x}$ is the electric field. This field consists of two components:

$$
\mathrm{E}_{\mathrm{x}}=\mathrm{E}_{0}+\mathrm{E}_{\mathrm{sc}} \cos \left(\overrightarrow{\mathrm{K}_{\mathrm{G}}} \cdot \overrightarrow{\mathrm{r}}+\phi\right)
$$

$E_{0}$ is the applied electric field and $E_{s c}$ is the space charge field which depend of the diffusion and saturation fields:

$$
E_{s c}=m E_{q}\left[\frac{E_{0}{ }^{2}+E_{d}{ }^{2}}{E_{0}{ }^{2}+\left(E_{d}+E_{q}\right)^{2}}\right]^{1 / 2}
$$

In Eq. (6) $E_{0}$ Is the applied electric field of eq. (5), Ed is the diffusion field and Eq is an upper limit on the space charge field corresponding in a single trap model to saturation of available acceptor site (assuming monopolar charge transport in which electrons are the only mobile carriers).

The electric field of the two beams can be written as:

$$
\overrightarrow{\mathrm{E}}(\mathrm{x}, \mathrm{y}, \mathrm{z})=\overrightarrow{\mathrm{R}(\mathrm{z})} \mathrm{e}^{\mathrm{i} \overrightarrow{\mathrm{K}_{\mathrm{R}}} \cdot \overrightarrow{\mathrm{r}}}+\overrightarrow{\mathrm{S}(\mathrm{z})} \mathrm{e}^{\mathrm{i} \overrightarrow{\mathrm{K}_{\mathrm{S}}} \cdot \overrightarrow{\mathrm{r}}}
$$

The polarization states of the incident probe beam $\mathrm{R}$ and of the diffracted signal field $\mathrm{S}$ are two orthogonal linear polarization states which components is given by:

$$
\begin{gathered}
\overrightarrow{\mathrm{R}}=\hat{\mathrm{y}} \mathrm{R}_{\mathrm{E}}+\left(\hat{\mathrm{x}} \cos \theta_{\mathrm{R}}-\hat{z} \operatorname{sen} \theta_{\mathrm{R}}\right) \mathrm{R}_{\mathrm{M}} ; \\
\overrightarrow{\mathrm{S}}=\hat{\mathrm{y}} \mathrm{S}_{\mathrm{E}}+\left(\hat{\mathrm{x}} \cos \theta_{\mathrm{S}}-\hat{\mathrm{z}} \operatorname{sen} \theta_{\mathrm{S}}\right) S_{\mathrm{M}}
\end{gathered}
$$

The set of coupled wave equations can be derived now that structure of the light field has been defined. The optical activity tensor can be added to the permittivity tensor, the constitutive relation for the $\overrightarrow{\mathrm{K}_{\mathrm{G}}} \|<$ $001>$ orientation is:

$$
\left[\begin{array}{c}
\mathrm{D}_{M} \\
\mathrm{D}_{\mathrm{E}}
\end{array}\right]=\epsilon_{0}\left[\begin{array}{cc}
\epsilon & \text { ia } \\
-\mathrm{ia} & \epsilon+\Delta \epsilon
\end{array}\right]\left[\begin{array}{c}
\mathrm{E}_{\mathrm{M}} \\
\mathrm{E}_{\mathrm{E}}
\end{array}\right] ;
$$

where $\mathrm{a}$ is a parameter defined by $2 \mathrm{n}_{0} \rho / \mathrm{k}_{0}$.

Using the slowly varying envelope approximation derives the coupled wave equations. The resulting set of coupled wave equation is: 


$$
\begin{gathered}
\frac{\mathrm{DR}_{\mathrm{M}}}{\mathrm{dz}}=-\frac{\rho}{\cos \theta} \mathrm{R}_{\mathrm{E}} \\
\frac{\mathrm{dR}_{\mathrm{E}}}{\mathrm{dz}}=\frac{\rho}{\cos \theta} \mathrm{R}_{\mathrm{M}}+\mathrm{i} \frac{\mathrm{C}_{\mathrm{o}}}{\cos \theta} \mathrm{R}_{\mathrm{M}}+\mathrm{i} \frac{\mathrm{C}_{\mathrm{sc}}}{\cos \theta} \mathrm{S}_{\mathrm{E}} \mathrm{e}^{-\mathrm{i} \phi} \\
\frac{\mathrm{dS} \mathrm{S}_{\mathrm{M}}}{\mathrm{dz}}=-\frac{\rho}{\cos \theta} \mathrm{S}_{\mathrm{E}} \\
\frac{\mathrm{dS_{ \textrm {E } }}}{\mathrm{dz}}=\frac{\rho}{\cos \theta} \mathrm{S}_{\mathrm{M}}+\mathrm{i} \frac{\mathrm{C}_{\mathrm{o}}}{\cos \theta} \mathrm{S}_{\mathrm{E}}+\mathrm{i} \frac{\mathrm{C}_{\mathrm{sc}}}{\cos \theta} \mathrm{R}_{\mathrm{E}} \mathrm{e}^{\mathrm{i} \phi}
\end{gathered}
$$

where $\rho$ is the optical rotatory power and:

$$
\begin{gathered}
\mathrm{C}_{\mathrm{o}}=\frac{\mathrm{\pi n}_{0}{ }^{3}}{\lambda} \mathrm{r}_{41} \mathrm{E}_{0} \\
\mathrm{C}_{\mathrm{sc}}=\frac{\pi \mathrm{n}_{0}^{3}}{\lambda} \mathrm{r}_{41} \mathrm{E}_{\mathrm{sc}} \frac{1}{2}
\end{gathered}
$$

For the longitudinal configuration we obtained the diffraction efficiency $\eta$, defined by:

$$
\eta=\frac{I_{d}(z)}{I_{i}(0)}
$$

where $I_{d}(z)$ is the intensity of the diffraction light, $I_{i}(z)$ is the intensity of the incident light.

For theoretical analysis was used the Runge-Kutta method and its algorithm in Matlab.

TABLE 1. Parameter for BTO [3,7-9] taken for our calculations

\begin{tabular}{|c|c|}
\hline \hline & BT0 \\
\hline \hline$\epsilon$ Dielectric constant & 47 \\
$n_{o}$ refraction index & 2.58 \\
$r_{41}$ electro optic coefficient $\left(\mathrm{mV}^{-1}\right)$ & $5.1 \times 10^{-12}$ \\
$N_{A}$ Acceptor density $\left(\mathrm{m}^{-3}\right)$ & $4 \times 10^{-22}$ \\
$\rho$ Optical Activity ${ }^{-1} \mathrm{~cm}^{-1}(\lambda=632 \mathrm{~nm})$ & 65 \\
\hline \hline
\end{tabular}

\section{Results and Discussion}

In Fig. 2 we show the result for the dependence of the diffraction efficiency on the sample thickness for different applied field for a BTO grating using red light $(632 \mathrm{~nm})$ for reading. For this case, $\mathrm{K}_{\mathrm{G}} \| l<001>$; $\mathrm{m}=0.9$ and $\Lambda=1 \mu \mathrm{m} ; 10 \mu \mathrm{m}$; the largest value of the diffraction efficiency occurs for an applied field of 10 $\mathrm{kV} / \mathrm{cm}$. We can see that the smallest of diffraction efficiency occurs for the smallest value of the applied field: $1 \mathrm{kV} / \mathrm{cm}$.
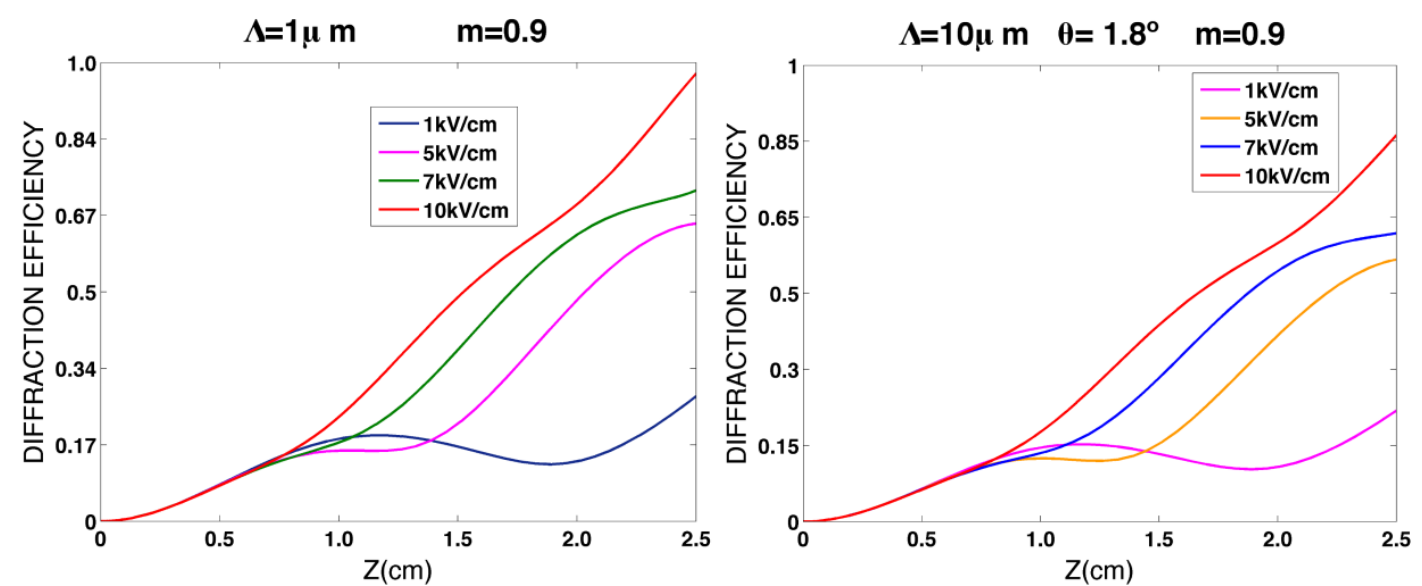

Fig. 2. BTO crystal diffraction efficiency in terms of the crystal thicknesses using red read-out light and different applied electric fields $\mathrm{Ea}=1 \mathrm{kV} / \mathrm{cm}, 5 \mathrm{kV} / \mathrm{cm}, 7 \mathrm{kV} / \mathrm{cm}$ y $10 \mathrm{kV} / \mathrm{cm}, \epsilon=47, \mathrm{~m}=0.9$, at various values (a) $\Lambda=1 \mu \mathrm{m}$, (b) $\Lambda=10 \mu \mathrm{m}$.

In Fig. 3 we show the result for the dependence of the diffraction efficiency on the sample thickness for a BTO grating using red light $(632 \mathrm{~nm})$ for reading for different grating. For this case, $\mathrm{K}_{\mathrm{G}} \| l<001>; \mathrm{E}_{\mathrm{a}}=10$ 
$\mathrm{Kv} / \mathrm{cm} ; \mathrm{m}=0.9$ and $\mathrm{m}=0.3$; the largest value of the diffraction efficiency occurs for a grating period of 10 microns and. We can see that for all values of the grating period considered, the diffraction efficiency reaches a maximum value and the smallest of these occurs for the smallest value of the grating period: 1 micron.
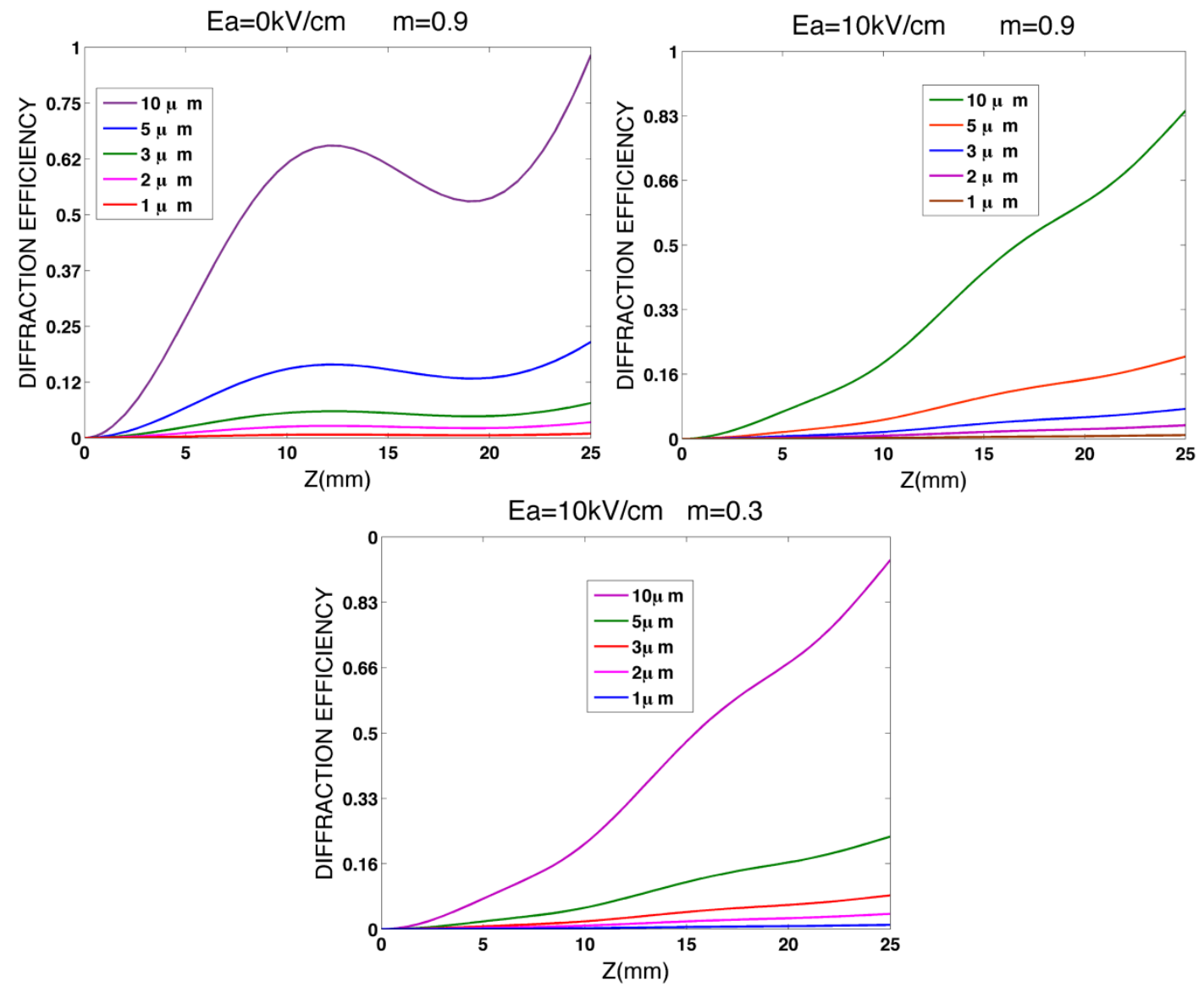

Fig. 3. BTO crystal diffraction efficiency in terms of the crystal thicknesses using red read-out light and different grating period: $\Lambda=1 \mu \mathrm{m}, 2 \mu \mathrm{m}, 3 \mu \mathrm{m}, 5 \mu \mathrm{m}, 10 \mu \mathrm{m}$, at various values of (a) $\mathrm{m}=0.9, \mathrm{Ea}=0 \mathrm{kV} / \mathrm{cm}$ (b) $\mathrm{m}=0.9, \mathrm{Ea}=10 \mathrm{kV} / \mathrm{cm}$ (c) m=0.3, Ea=10kV/cm

In Fig. 4 we show the result for the dependence of the diffraction efficiency on sample thickness for a BTO grating using red-out light $(632 \mathrm{~nm})$ for reading for different modulations. For this case: $\mathrm{K}_{\mathrm{G}} \|<001>$; $\mathrm{E}_{\mathrm{a}}=10$ $\mathrm{Kv} / \mathrm{cm} ; \Lambda=1 \mu \mathrm{m} ; 10 \mu \mathrm{m}$. In this case, the largest value of the diffraction efficiency occurs for a modulation of 0.9 . For all the range of values of sample thickness considered, the modulation corresponding to 0.9 maintains the largest value for the diffraction efficiency.
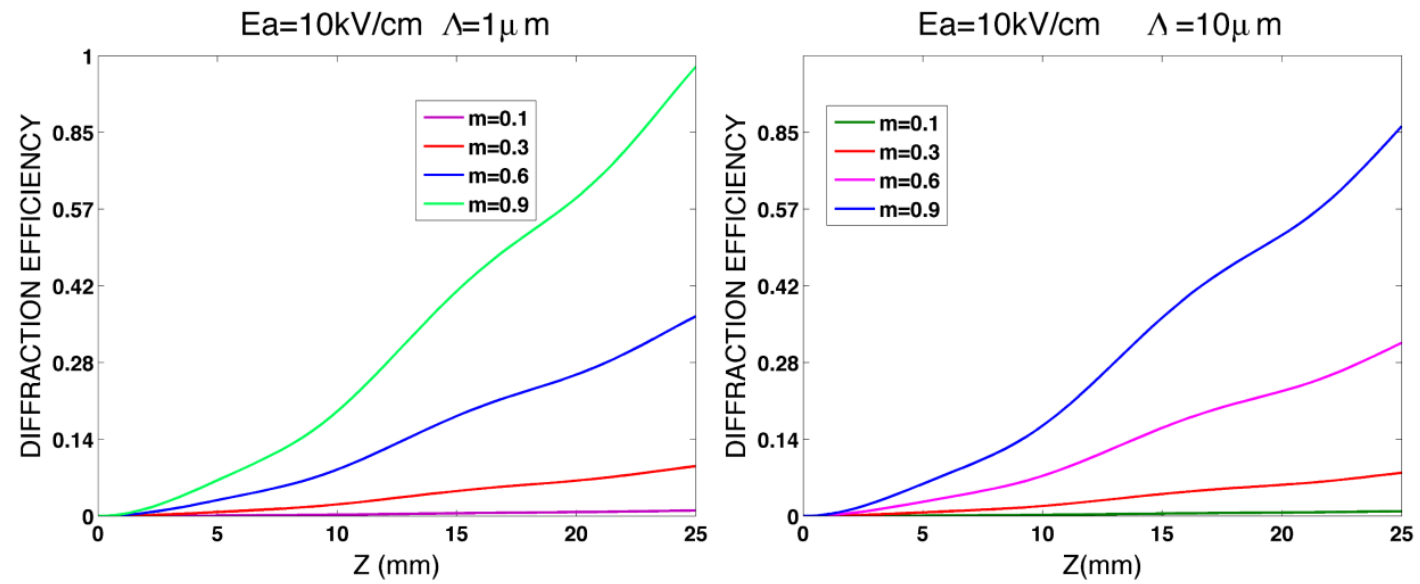

Fig 4. BTO crystal diffraction efficiency in terms of the crystal thicknesses using red read-out light and different modulations, $\mathrm{m}=0.1$, $0.3,0.6,0.9$ at various values of (a) $\Lambda=1 \mu \mathrm{m}$, (b) $\Lambda=10 \mu \mathrm{m}$. 


\section{Conclusions}

We studied the diffraction efficiency in non-moving transmission gratings, in Bragg regime in longitudinal configuration in BTO crystal. A set of coupled-wave equations has been derived for longitudinal holographic orientation in crystal BTO of sillenite family. These equations allow an analysis to be made of the polarization properties of light diffraction including the effects of concomitant optical rotatory power. In the date analytic we used red light for the reading. We considered the birefringence, coupling electrooptic, optical activity, fringe period, different fields applied, different modulations and the polarization beams.

The results show that for the field applied of $1 \mathrm{Kv} / \mathrm{cm}$ corresponded to the small diffraction efficiency, for the fringe period of $10 \mu \mathrm{m}$ the diffraction efficiency is greater and for a modulation of 0.1 the diffraction efficiency is smallest.

\section{Acknowledgements}

This research was performed under the grants:PR130-00-033 (GA160-BP-II-2013-2.1.2.2.1) y PR130-00001 (GA160-CM-I-2014-2.1.2.2.1)-Unipamplona, Astrid Villamizar acknowledges financial support of the Vicerrectoría de Investigaciones of the Universidad de Pamplona (Pamplona-Colombia). Portions of this work were presented at the IX RIAO/OPTILAS in Pucón, Chile 2016" 